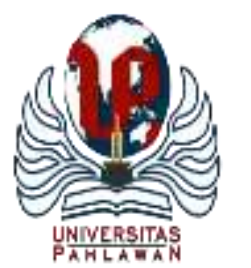

Edukatif : Jurnal Ilmu Pendidikan Volume 4 Nomor 1 Tahun 2022 Halm 952 - 962 EDUKATIF: JURNAL ILMU PENDIDIKAN

Research \& Learning in Education

https://edukatif.org/index.php/edukatif/index

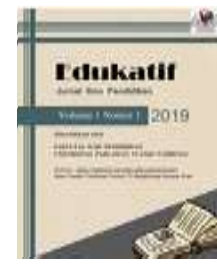

\title{
Persepsi Tenaga Kependidikan Tentang Merdeka Belajar- Kampus Merdeka Studi Kasus di Universitas Flores Ende
}

\author{
Falentina Lucia Banda ${ }^{1 凶}$, Ernesta Leha ${ }^{2}$, Reyna Virginia Nona ${ }^{3}$, Lely Suryani ${ }^{4}$, Konstantinus \\ Denny Pareira Meke ${ }^{5}$, Philipus N. Supardi ${ }^{6}$ \\ Universitas Flores, Indonesia ${ }^{1,2,3,4,5,6}$ \\ E-mail :.mmyosep@gmail.com ${ }^{1}, \underline{\text { ernestaleha@gmail.com }}^{2}$, reynamayosuku@gmail.com $^{3}$, \\ lelipany@gmail.com ${ }^{4}, \underline{\text { dennyz.pareira@gmail.com }}^{5}, \underline{\text { ardytobong@gmail.com }}^{6}$
}

\begin{abstract}
Abstrak
Tujuan penelitian ini adalah mengukur persepsi Tenaga Kependidikan tentang Kebijakan Merdeka BelajarKampus Merdeka di Universitas Flores. Survei dilakukan terhadap 118 Tenaga Kependidikan, menggunakan instrumen pada aplikasi SPADA Dikti. Hasil penelitian menunjukkan bahwa hanya 13\% Tenaga Kependidikan Universitas Flores mengetahui kebijakan MBKM secara keseluruhan dan mengetahui kebijakan MBKM melalui media masa sebesar 21\%. Pemahaman Implementasi tentang MBKM masih rendah yaitu 18\%, bersedia ikut berpartisipasi secara penuh $24 \%$ dan $29 \%$ merasa puas dan ingin lebih jauh berpartisipasi. Hasil survei menujukkan bahwa MBKM akan meningkatkan soff skill dan hard skill mahasiswa dengan sangat baik sebesar $13 \%$ dan peningkatan dengan sangat baik bagi dosen sebesar 47\%. Hasil survei menunjukkan 52\% Tenaga Kependidkan mengetahui adanya pedoman MBKM di level Universitas dan menyatakan manfaat implementasi MBKM dalam pemenuhan CPL sebesar 63\%. Perbandingan signifikan peningkatan kualitas lulusan menghadapi dunia paska kampus sebelum MBKM hasil survei menunjukkan 10\% menyatakan bahwa ada peningkatan dengan sangat baik terhadap kualitas lulusan dan $81 \%$ Tendik merekomendasikan agar program MBKM diikuti mahasiswa Universitas Flores.
\end{abstract}

Kata Kunci: Merdeka Belajar, Kampus Merdeka, Tenaga Kependidikan.

\section{Abstract}

The purpose of this study was to measure the perception of education personnel about the Independent Learning Policy-Independent Campus at the University of Flores. The survey was conducted on 118 Education Personnel, using instruments in the SPADA Dikti application. The results showed that only 13\% of the education staff at the University of Flores knew about MBKM policies as a whole and $21 \%$ knew about MBKM policies through mass media. Implementation understanding of MBKM is still low at 18\%, 24\% are willing to participate fully and $29 \%$ are satisfied and want to participate further. The survey results show that MBKM will improve students' soft skills and hard skills very well by $13 \%$ and a very good increase for lecturers by $47 \%$. The survey results show that $52 \%$ of education personnel are aware of the MBKM guidelines at the university level and state the benefits of implementing MBKM in fulfilling CPL are 63\%. A significant comparison of the improvement in the quality of graduates facing the post-campus world before the MBKM survey results showed 10\% stated that there was a very good improvement in the quality of graduates and $81 \%$ Tendik recommended that the MBKM program be followed by Flores University students. Keywords: Independent Learning, Independent Campus, Education Staff.

Copyright (c) 2022 Falentina Lucia Banda, Ernesta Leha, Reyna Virginia Nona, Lely Suryani, Konstantinus Denny Pareira Meke, Philipus N. Supardi

$\triangle$ Corresponding author

Email : mmyosep@gmail.com

DOI : https://doi.org/10.31004/edukatif.v4i1.2055

ISSN 2656-8063 (Media Cetak)

ISSN 2656-8071 (Media Online) 
953 Persepsi Tenaga Kependidikan Tentang Merdeka Belajar- Kampus Merdeka Studi Kasus di Universitas Flores Ende - Falentina Lucia Banda, Ernesta Leha, Reyna Virginia Nona, Lely Suryani, Konstantinus Denny Pareira Meke, Philipus N. Supardi

DOI: https://doi.org/10.31004/edukatif.v4i1.2055

\section{PENDAHULUAN}

Globalisasi menyebabkan perkembangan ilmu pengetahuan dan teknologi yang sangat pesat, dibutuhkan pelayanan kepada masyarakat yang efektif, efisien dan transparan, (Hartati et al., 2022). Perkembangan IPTEK harus diikuti oleh peningkatan sumber daya manusia terutama generasi muda, yang mampu beradaptasi secara cepat dan tepat, agar menguasai teknologi yang berkembang, dengan pengetahuan yang dimiliki yang mengakar pada budaya nasional Indonesia, (Riyanti et al., 2022). Pendidikan harus mendapatkan tempat istimewa dan penting dalam pembangunan bangsa, (Jalaluddin \& Idi, 2011).

Perguruan tinggi dituntut untuk mampu menghasilkan lulusan yang siap kerja dan mampu beradaptasi dengan lingkungan setelah paska kampus atau universitas kehidupan. (Leuhery, 2018) menjelaskan kualitas sumber daya manusia merupakan faktor terpenting dalam keberhasilan sebuah organisasi, semakin tinggi kualitas sumber daya manusia semakin baik prestasi kerja yang akan dihasilkan. Kualitas lulusan sangat dipengaruhi oleh kualitas sumber daya yang ada di perguruan tinggi seperti sumber daya manusianya seperti dosen (tenaga pendidik) dan karyawan (tenaga kependidikan), (Nulhaqim et al., 2016; Rosmiati, 2020) dan sumber daya pendukung lainnya seperti sarana dan prasarana.

Pemerintah mencetuskan berbagai program untuk meningkatkan kualitas lulusan, salah satu program yang ditetapkan adalah program Merdeka Belajar Kampus Merdeka (MBKM) melalui Peraturan Menteri Pendidikan dan Kebudayaan (Permendikbud) Republik Indonesia Nomor 3 Tahun 2020 (Indonesia, 2003).

Universitas Flores secara kelembagaan di tingkat universitas telah menyiapkan dokumen kebijakan MBKM di Universitas Flores melalui Surat Keputusan (Rektor, n.d.) nomor 02 Tahun 2021 tentang Penetapan Pedoman Penyusunan Kurikulum MBKM, hal ini menanggapi kebijakan pemerintah Republik Indonesia yang diharapkan memberikan kontribusi bagi kemajuan perguruan tinggi di Indonesia (Faiz, 2021). Prodi dan fakultas yang ada di Universitas Flores belum semuanya memiliki kelengkapan dokumen MBKM dan kerjasama yang dapat digunakan sebagai pedoman bagi semua pihak yang terlibat dalam menjalankan MBKM. Perubahan kebijakan pemerintah melalui MBKM disesuaikan dengan perkembangan zaman, (Suryaman et al., 2020) mengatakan MBKM berupaya menjawab isu kecerdasan artifisial yang kini makin terasa saat pandemi berlangsung.

Tenaga Kependidikan (Tendik) merupakan salah satu komponen strategik di perguruan tinggi yang menunjang pelaksanaan tridarma perguruan tinggi. Peraturan pemerintah nomor 38 tahun 1992 (Pemerintah, 1992) dijelaskan bahwa tenaga kependidikan merupakan komponen penting dalam sistem pendidikan nasional. Tendik merupakan salah satu pihak yang turut terlibat dalam kegiatan MBKM, dimana kebijakan MBKM sangat menekankan level kompetensi baik dosen, tendik maupun tenaga administrasi yang tidak memegang jabatan fungsional. Keterlibatan Tendik dalam memainkan perannya secara baik tentu dapat memberikan dampak pada keberhasikan kegiatan MBKM. Peran Tendik dalam kegiatan MBKM dapat diwujudkan dalam berbagai kegiatan atau peran seperti keterlibatannya dalam menjalankan fungsi administrasi, pengeloaan yang dimulai dengan keterlibatannya dalam berbagai rapat koordinasi dan sosialisasi serta penyusunan pedoman MBKM, pengawasan, dan pelayanan teknis.

Tendik di Universitas Flores berjumlah 118 orang yang tersebar di berbagai fakultas dan prodi. Universitas Flores mempunyai 7 fakultas dan 16 program studi. Menindaklanjuti SK Rektor, program studi melakukan revisi kurikulum menyesuaian program MBKM, walaupun kesempatan mahasiswa untuk belajar di program studi lain di dalam perguruan tinggi dan di program studi yang sama di perguruan tinggi lain belum dilaksanakan, 33 orang mahasiswa telah mengikuti kampus mengajar dan 5 orang dosen melakukan riset keilmuan di tahun 2021. Wujud MBKM telah dilaksanakan seperti dosen mengajar di luar kampus, praktisi mengajar di kampus, kuliah kerja nyata tematik, praktek kerja lapangan, magang di desa dan di industri, 
954 Persepsi Tenaga Kependidikan Tentang Merdeka Belajar-Kampus Merdeka Studi Kasus di Universitas Flores Ende - Falentina Lucia Banda, Ernesta Leha, Reyna Virginia Nona, Lely Suryani, Konstantinus Denny Pareira Meke, Philipus N. Supardi

DOI: https://doi.org/10.31004/edukatif.v4i1.2055

lembaga swadaya masyarakat, lembaga pemerintah serta berbagai kegiatan pengabdian masyarakat yang dilakukan dosen bersama mahasiswa (Suryaman, 2020; Tohir, 2020).

Tendik di Universitas Flores berperan melancarkan kegiatan dosen dan mahasiswa melalui perannya sebagai administrasi, pengeloaan yang dimulai dengan keterlibatannya dalam berbagai rapat koordinasi untuk berbagai kegiatan tridarma yang dilakukan oleh civitas akademik maupun praktisi, (Kharis, 2010).

Penelitian sebelumnya terkait MBKM telah dilakukan terhadap mahasiswa, (Purwono dkk, 2021, Nyoto, 2021, Rosmiati dkk, 2021, Putri dkk, 2021). Penelitian persepsi MBKM pada Tendik belum banyak dilakukan, Nasrullah dkk, (2021) menunjukkan bahwa pengetahuan tenaga kependidikan tentang kebijakan MBKM, jumlah semester terkait MBKM masih rendah dan sumber informasi MBKM melalui sosialisasi internal perguruan tinggi dan sebagian besar sudah mengetahui adanya pedoman kebijakan di perguruan tingginya terkait MBKM. Penelitian ini dilakukan untuk mengetahui persepsi Tendik terhadap pelaksanaan MBKM di Universitas Flores. Rensra Kemendikbud 2020-2024 sasaran pengembangan pendidikan tinggi adalah meningkatkan kualitas pembelajaran, meningkatkan kualitas dosen dan tenaga kependidikan dan tata kelola Ditjend Pendidikan Tinggi yang berkualitas (Peraturan Menteri Pendidikan dan kebudayaan Republik Indonesia Nomor 22 tahun 2020). Dalam Permendikbud diatas salah satu sasaran peningkatan kualitas perguruan tinggi adalah meningkatkan kualitas tenaga kependidikan. Dalam implementasi MBKM di Universitas Flores diharapkan Tendik mempunyai pemahaman yang baik tentang MBKM. Pada penelitian sebelumnya survei kepada Tendik persepsi hanya pada jumlah semester di luar prodi, sumber informasi kebijakan MBKM dan pedoman kebijakan MBKM di level PT. Pada penelitian ini melalui aplikasi SPADA Dikti, persepsi Tendik diteliti lebih luas yaitu mulai dari sumber informasi MBKM sampai pada keterlibatan Tendik dalam kegiatan MBKM sampai pada manfaat MBKM bagi Dosen dan mahsiswa.

Berdasarkan uraian yang telah dipaparkan maka perlu dilakukan penelitian untuk mengetahui persepsi Tendik terhadap pelaksanaan program MBKM di Universitas Flores, agar dapat menghasilkan gambaran pemahaman maupun kesiapan Tendik terhadap pelaksanaan MBKM untuk ditemukan akar masalah dan strategi guna mengoptimalkan pelaksanaan MBKM di Universitas Flores.

\section{METODE PENELITIAN}

Penelitian ini dilakukan melalui penelitian deskriptif dengan metode survei menggunakan kuesioner. Sumber data diperoleh dari populasi menggunakan kuesioner yang langsung diisi responden dari aplikasi SPADA Dikti Kementrian Pendidikan, Kebudayaan, Riset dan Teknologi Republik Indonesia dari tanggal 15 desember sampai 21 Desember 2021. Data yang diperoleh dari hasil survei sebanyak 118 Tendik Universitas Flores. Data tersebut akan dioleh secara deskriptif yang menggambarkan persepsi Tendik tentang program MBKM di Universitas Flores. Kemudian data dikumpulkan, disusun dan dikatagorikan (Fuadi, 2021) (Fuadi \& Aswita, 2021). Tolok ukur yang digunakan dalam penelitian ini adalah kuesioner yang tersedia pada aplikasi SPADA Dikti, yang berisi sejumlah pernyataan yang harus dipilih oleh Tendik.

\section{HASIL DAN PEMBAHASAN PENELITIAN}

Hasil penelitian menunjukkan bahwa pemahaman Tendik tentang kebijakan Merdeka Belajar-Kampus Merdeka (MBKM)), diketahui bahwa 13\% sudah mengetahui kebijakan MBKM secara keseluruhan, 23\% mengetahui sebagian besar isi kebijakan MBKM, 44\% hanya mengetahui sedikit mengenai MBKM, namun masih terdapat $20 \%$ yang belum mengetahui sama sekali tentang kebijakan MBKM seperti pada data Gambar 1 dibawah ini: 


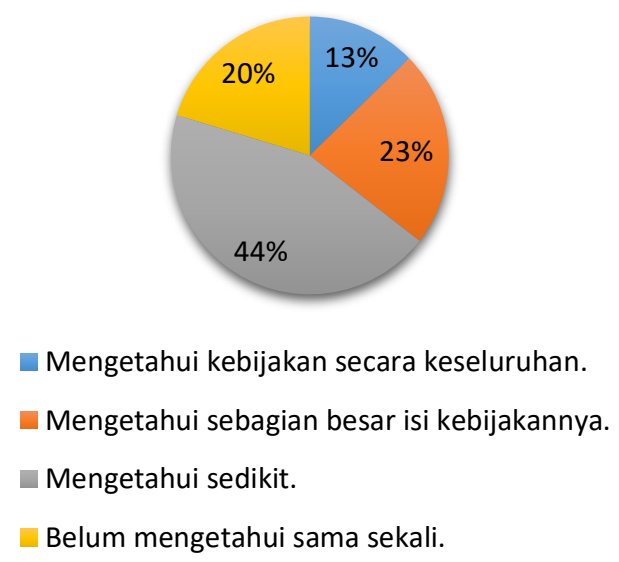

\section{Gambar 1 Pemahaman tentang kebijakan MBKM}

Berdasarkan data pada Gambar 1 maka perlu ada tindak lanjut dari pelaksanaan program MBKM untuk mensosialisasikan informasi mengenai kebijakan hingga pada tataran program studi dan unit-unit yang terlibat. Sedangkan penyesuaian bentuk kegiatan MBKM di luar perguruan tinggi baru $21 \%$ Tendik mengetahui bahwa pelaksanaannya 2 semester atau setara dengan 40 SKS.

Tendik memperoleh informasi tentang MBKM secara berturut-turut hasil survei menunjukkan bahwa $21 \%$ Tendik di Universitas Flores mendapatkan sumber informasi dari media masa, $20 \%$ memperoleh informasi dari kanal daring Kemendikbud, 19\% dari Kanal daring Perguruan Tinggi, 18\% dari kegiatan sosialisasi luring/daring yang diselenggarakan oleh Perguruan Tinggi, $12 \%$ dari sosialisasi luring/daring yang diselenggarakan oleh Kemendikbud, dan 10\% dari kanal komunikasi komunitas (alumni dan dosen). Hasil ini menunjukkan bahwa diperlukan sosialisasi ke Tendik di Universitas Flores tentang program MBKM, karena keberhasilan pelaksanaan MBKM perlu adanya pemahaman yang sama baik Dosen, Tendik maupun Mahasiswa. Di sisi lain 68\% Tendik mengetahui program-program terdahulu yang sesuai bentuk kegiatan MBKM pada program studinya seperti Kuliah Kerja Nyata, Magang, PPL, Kampus Mengajar dan PKL.

Pengetahuan Tendik terhadap pernyataan jumlah SKS yang diakui /disetarakan dengan bentuk kegiatan Pembelajaran MBKM diketahui bahwa baru 12\% Tendik yang mengetahui bahwa jumlah sks yang disetarakan dengan MBKM adalah 51-60 sks. Sedangkan sisanya belum memiliki pengetahun yang benar tentang jumlah sks yang disetarakan dengan MBKM. Hasil survei ini juga menunjukkan bahwa masih banyak yang belum memahami secara baik dan benar tentang MBKM khususnya yang berkaitan dengan jumlah sks yang disetarakan dengan bentuk kegiatan pembelajaran MBKM.

Hasil survei terkait pernyataan ketersediaan dokumen kebijakan kurikulum yang memfasilitasi MBKM (dalam bentuk peraturan rektor: panduan akademik atau panduan implementasi MBKM, kurikulum prodi untuk memfasilitasi MBKM), diketahui bahwa 24\% Tendik yang turut terlibat dalam mempersiapkan MBKM, $36 \%$ telah berkontribusi dalam diskusi/rapat/workshop terkait persiapan implementasi MBKM. Terdapat 21\% yang mengetahui informasi tetapi kurang tertarik untuk mengikutinya. Namun masih terdapat $19 \%$ Tendik yang tidak mengetahui adanya aktivitas persiapan implementasi MBKM di perguruan tinggi dan program studi.

Pengetahuan dan pemahaman tentang konsep MBKM untuk pendidikan tinggi secara umum Tendik telah mengetahui namun dalam pelaksanaannya belum memahami secara detail mengenai konsep MBKM. Berikut ini adalah hasil survey persepsi Tendik terhadap pernyataan ketersediaan dokumen kebijakan terkait kurikulum yang memfasilitasi MBKM (dalam bentuk peraturan rektor: panduan akademik atau panduan implementasi MBKM, kurikulum prodi untuk memfasilitasi MBKM) tampak pada Gambar 2. 


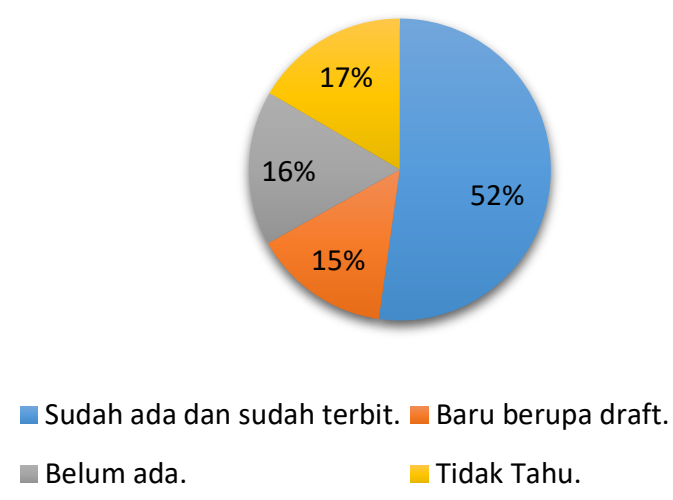

Gambar 2 Pemahaman tentang kepemilikan dokumen MBKM

Data pada Gambar 2 menunjukkan bahwa 52\% Tendik di Universitas Flores sudah mengetahui ketersediaan dokumen kebijakan terkait kurikulum yang memfasilitasi MBKM, 15\% mengetahui baru dalam bentuk draf, $16 \%$ menyatakan belum memiliki dokumen, dan terdapat $17 \%$ tidak mengetahui tentang ketersediaan dokumen. Hasil survei ini juga menunjukkan bahwa sosialiasi perlu dilakukan sampai ke prodi sebagai ujung tombak pelaksanaan MBKM dimana Tendik terlibat urusan administrasi prodi. Keterlibatan Tendik membantu program studi dalam melakukan perhitungan/penyetaraan sks kegiatan MBKM diketahui bahwa 71\% Tendik di Universitas Flores sudah pernah terlibat dalam konversi sks yang berkaitan dengan MBKM, sedangkan 29\% lainnya belum pernah terlibat.

Universitas Flores mempunyai Buku Panduan MBKM yang sudah diterbitkan pada bulan Agustus 2021, hasil survei menunjukkan bahwa 62\% Tendik di Universitas Flores belum mempelajari Buku Panduan MBKM, sedangkan terdapat $38 \%$ yang sudah mempelajarinya. Keberhasilan pelaksanaan MBKM juga dipengaruhi oleh pemahaman yang baik dari semua pihak yang melaksanakan MBKM termasuk Tendik yang membantu mengurusi administrasi kegiatan MBKM baik di tingkat program studi maupun sampai pada level Universitas.

Hasil survei persepsi Tendik terhadap pernyataan keterlibatan dalam mengikuti sosialisasi program MBKM baik langsung maupun mengikuti melalui youtube ditjen dikti, diketahui bahwa 53\% telah berpartisipasi terlibat dalam sosialisasi MBKM, namun masih terdapat $47 \%$ yang belum terlibat. Hal ini disebabkan oleh belum semua program studi mempersiapkan dokumen dan mensosialisasikannya kepada semua yang pihak yang terlibat di dalam kegiatan MBKM (Dari \& Yulhendri, 2019; Hidayatullah, 2021).

Hasil survei persepsi Tendik terhadap pernyataan pemahaman terhadap konsep MBKM dapat diketahui bahwa baru 18\% sudah mengetahui dan memahami MBKM, sedangkan 32\% sudah mengetahui namun belum paham terhadap MBKM, 35\% sudah tahu dan memahami dan 15\% belum mengetahui dan belum memahami MBKM. Dari hasil survei diatas diketahui bahwa 85\% Tendik sudah mengetahui MBKM walaupun pemahaman tentang MBKM masih bervariasi. Selanjutnya persepsi Tendik terhadap pertanyaan sejauh mana program MBKM berdampak terhadap proses pembelajaran mahasiswa berdasarkan hasil survei diketahui bahwa 13\% Tendik memberikan respon bahwa program MBKM dapat menyebabkan adanya peningkatan dengan sangat baik terhadap proses pembelajaran mahasiswa, 25\% menyatakan bahwa program MBKM dapat berdampak pada peningkatan proses pembelajaran dengan baik, $48 \%$ menyatakan ada peningkatan cukup baik pada proses pembelajaran, namun masih terdapat $10 \%$ yang menyatakan ada peningkatan pada proses pembelajaran tapi kurang baik dan masih terdapat $4 \%$ yang memberikan respon bahwa tidak ada peningkatan sama sekali dari dampak program MBKM terhadap proses pembelajaran. Dari hasil diatas dapat disimpulkan bahwa $86 \%$ Tendik menyatakan MBKM berdampak pada peningkatan pembelajaran mahasiswa, sehingga 
957 Persepsi Tenaga Kependidikan Tentang Merdeka Belajar-Kampus Merdeka Studi Kasus di Universitas Flores Ende - Falentina Lucia Banda, Ernesta Leha, Reyna Virginia Nona, Lely Suryani, Konstantinus Denny Pareira Meke, Philipus N. Supardi

DOI: https://doi.org/10.31004/edukatif.v4i1.2055

Tendik tidak hanya mendukung pelaksanaan administrasi pelaksanaan MBKM tapi juga terlibat dalam sosialisasi manfaat MBKM kepada mahasiswa sebagai pusat pembelajaran MBKM yang esensisal.

Hasil survei persepsi Tendik terhadap implementasi program MBKM memberikan peningkatan terhadap hard-skill dan soft-skill bagi mahasiswa, menunjukkan Tendik menyatakan bahwa ada peningkatan dengan sangat baik sebesar $13 \%$, ada peningkatan dengan baik $31 \%$, ada peningkatan yang cukup baik sebesar $42 \%$ namun masih terdapat $9 \%$ menunjukkan ada peningkatan tetapi kurang baik dan 5\% menyatakan tidak ada peningkatan sama sekali seperti tampak pada Gambar 3 berikut:

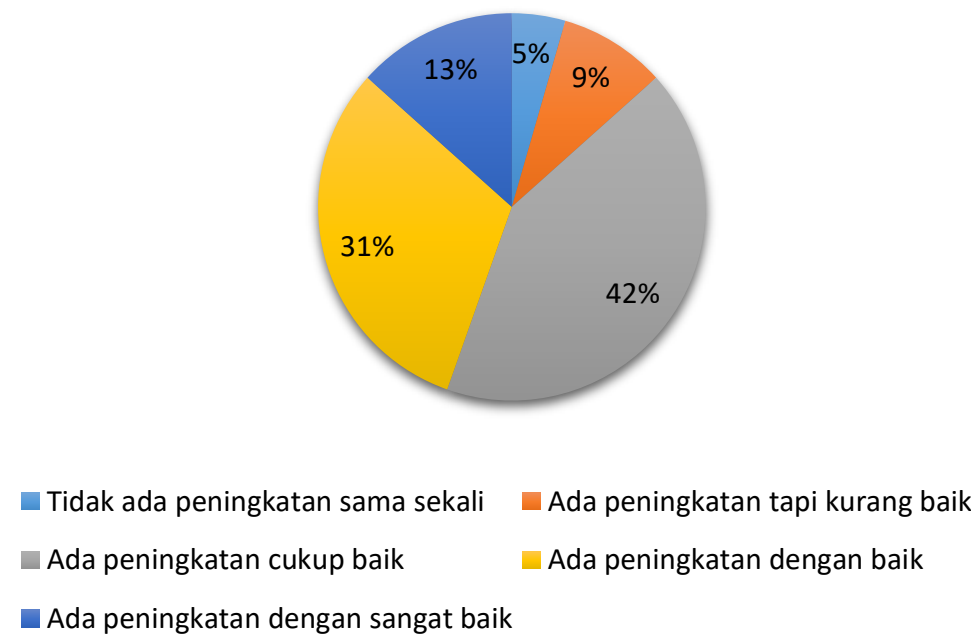

Gambar 3 Pemahaman Tentang Manfaat MBKM Berkaitan Dengan Peningkatan Hard Skill Dan Soft Skill Mahasiswa

Berikut ini adalah persepsi terhadap pertanyaan apakah Perguruan Tinggi memberikan sosialisasi dan pembekalan terkait implementasi program MBKM di Universitas Flores tampak pada Gambar 4

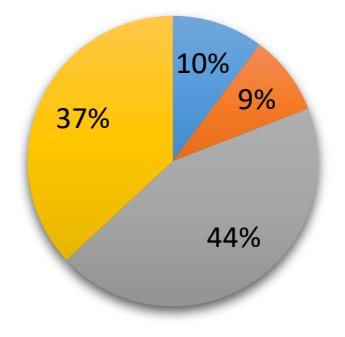

Tidak ada pembekalan sama sekali
Ada pembekalan tapi kurang baik
Ada pembekalan dengan baik
Ada pembekalan dengan baik dan mendorong partisipasi tenaga kependidikan

\section{Gambar 4 Sosialisasi dan pembekalan terkait implementasi program MKBM di Perguruan Tinggi}

Hasil survei menunjukkan bahwa 37\% menyatakan bahwa ada pembekalan dengan baik dan mendorong partisipasi tenaga kependidikan, dan 44\% menyatakan bahwa ada pembekalan dengan baik. Sedangkan 9\% menyatakan bahwa ada pembekalan tapi kurang baik, dan $10 \%$ yang menyatakan bahwa tidak ada pembekalan sama sekali. Hasil survei diatas menyatakan bahwa hampir $90 \%$ menyatakan ada pembekalan, Tendik 
958 Persepsi Tenaga Kependidikan Tentang Merdeka Belajar-Kampus Merdeka Studi Kasus di Universitas Flores Ende - Falentina Lucia Banda, Ernesta Leha, Reyna Virginia Nona, Lely Suryani, Konstantinus Denny Pareira Meke, Philipus N. Supardi

DOI: https://doi.org/10.31004/edukatif.v4i1.2055

didorong untuk ikut terlibat dalam kegiatan sosialisasi dan pembekalan untuk menunjang keberhasilan MBKM di Unversitas Flores. Sehingga Tendik akan menjawab tugas pokoknya sesuai dengan UndangUndang Nomor 20 Tahun 2003, Bab XI pasal 39 ayat 1 yang menyebutkan bahwa tenaga kependidikan bertugas melaksanakan administrasi, pengelolaan, pengembangan, pengawasan, dan pelayanan teknis untuk menunjang proses pendidikan pada suatu pendidikan.

Hasil survei persepsi Tendik terhadap pernyataan bahwa implementasi program MBKM berperan terhadap peningkatan kapasitas dan kemampuan tenaga Pendidik, dipaparkan berikut ini: 47\% Tendik menyatakan ada peningkatan dengan sangat baik, 31\% memilih ada peningkatan dengan baik, 15\% menyatakan tidak ada peningkatan sama sekali, 4\% ada peningkatan tetapi kurang baik dan sisanya $3 \%$ menyatakan tidak ada peningkatan sama sekali. Berdasarkan survei diatas disimpulkan $82 \%$ menyatakan ada peningkatan kapasistas dan kemampuan Tenaga Pendidik dalam implementasi program MBKM. Peningkatan kualitas mahasiswa melalui program MBKM, juga perlu meningkatkan kualitas dosen dan Tendik di Universitas Flores. Universitas Flores sudah mempunyai gedung kampus yang baik, sudah saatnya Universitas Flores mengembangkan sumber daya manusia unggul dan terpercaya sebagai mediator budaya sesuai dengan visi universitas Flores. Hasilnya dapat dilihat pada gambar 5 berikut
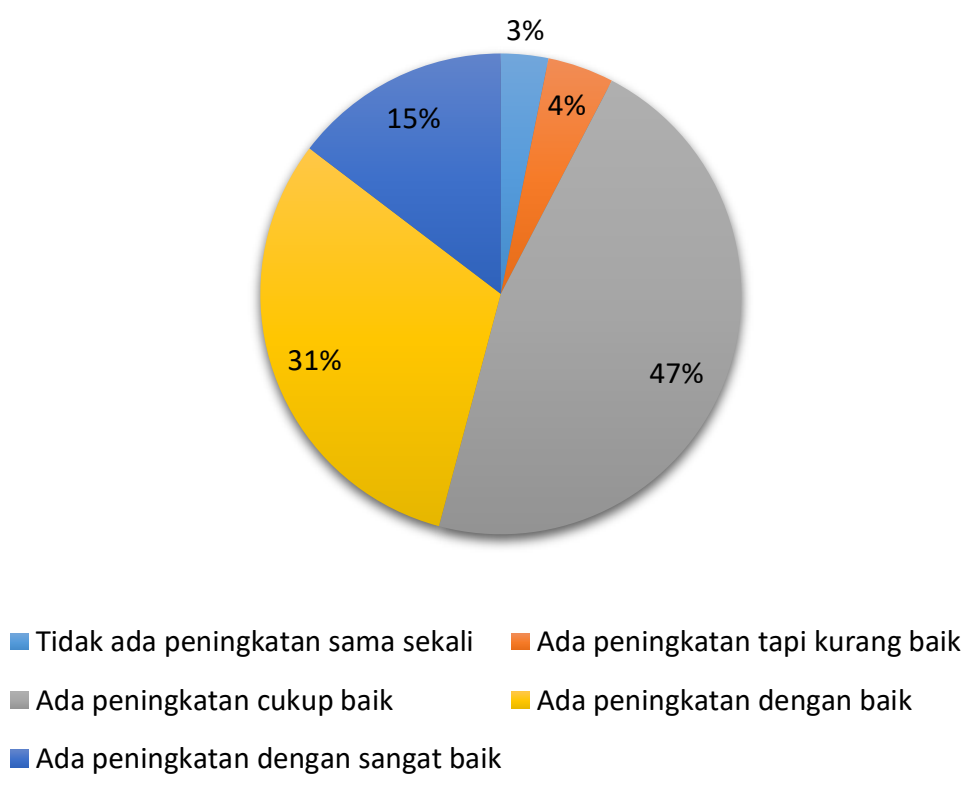

\section{Gambar 5 Implementasi program MBKM berperan peningkatan kapasistas dan kemampuan Tenaga pendidik}

Hasil survei persepsi Tendik terhadap pernyataan sejauh mana perguruan tinggi melibatkan Tendik dalam proses MBKM, dipaparkan pada gambar berikut: 
959 Persepsi Tenaga Kependidikan Tentang Merdeka Belajar-Kampus Merdeka Studi Kasus di Universitas Flores Ende - Falentina Lucia Banda, Ernesta Leha, Reyna Virginia Nona, Lely Suryani, Konstantinus Denny Pareira Meke, Philipus N. Supardi

DOI: https://doi.org/10.31004/edukatif.v4i1.2055
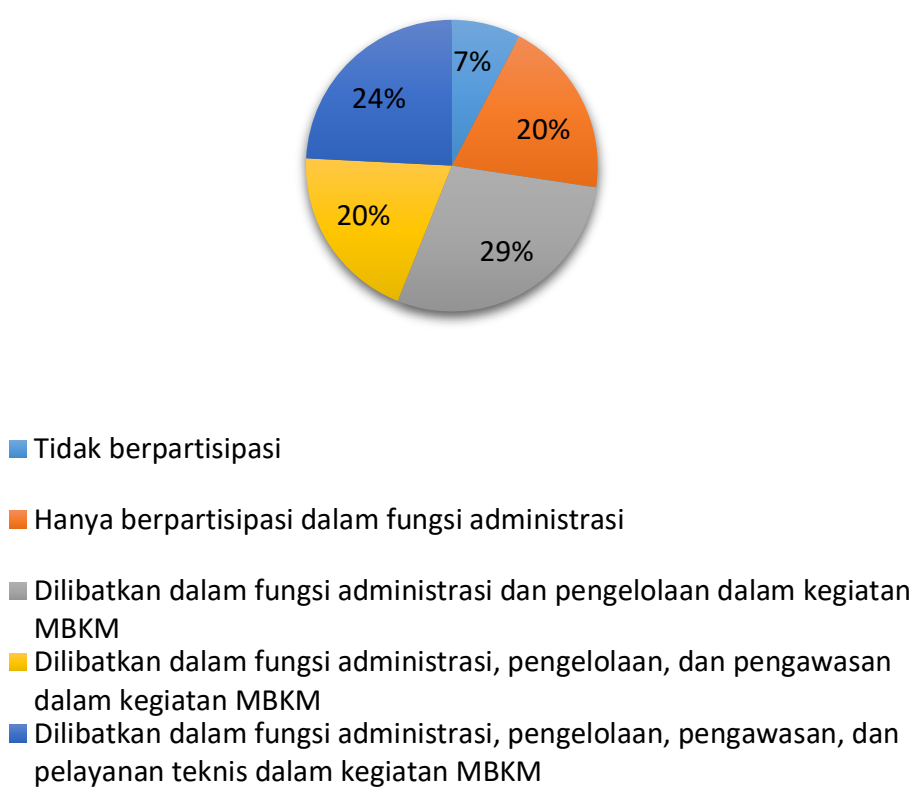

\section{Gambar 6 Keterlibatan dalam MBKM}

Tendik merupakan salah satu komponen yang turut berperan dalam kegiatan MBKM. Keterlibatannya dalam mendukung ketercapaian pembelajaran dapat diwujudkan dalam bentuk menjalankan fungsi administrasi, pengelolaan, pengawasan dan pelayanan teknis kegiatan MBKM. Hasil survei menunjukkan bahwa $24 \%$ telah dilibatkan dalam fungsi administrasi, pengelolaan, pengawasan, dan pelayanan teknis dalam kegiatan MBKM, 20\% telah dilibatkan dalam menjalankan kegiatan administrasi, pengelolaan dan pengawasan, 29\% hanya dilibatkan dalam fungsi administrasi dan pengelolaan, $20 \%$ hanya berpartisipasi dalam fungsi administrasi, namun masih terdapat $7 \%$ yang tidak diibatkan dalam kegiatan MBKM selama ini. Program MBKM adalah program baru sehingga dibutuhkan penyiapan dan peningkatan kapasistas sumber daya manusia, tidak hanya dosen sebagai tetapi juga Tendik.

Hasil survei persepsi Tendik terhadap pernyataan kepuasan dalam berpartisipasi dalam pelaksanaan program MBKM di Universitas Flores dipaparkan pada gambar berikut ini:

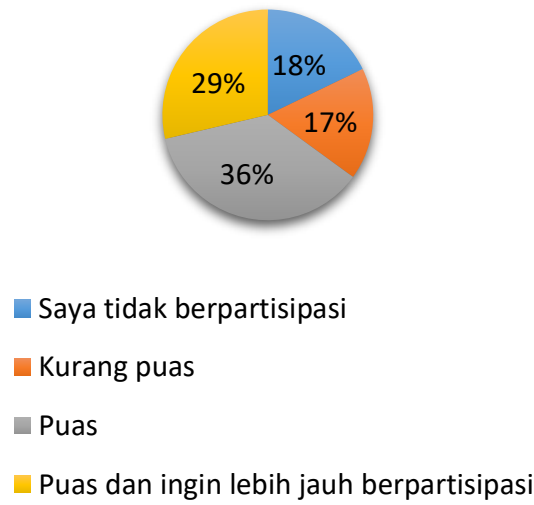

Gambar 7 Tingkat Kepuasan Dalam Pelaksanaan MBKM 
960 Persepsi Tenaga Kependidikan Tentang Merdeka Belajar- Kampus Merdeka Studi Kasus di Universitas Flores Ende - Falentina Lucia Banda, Ernesta Leha, Reyna Virginia Nona, Lely Suryani, Konstantinus Denny Pareira Meke, Philipus N. Supardi

DOI: https://doi.org/10.31004/edukatif.v4i1.2055

Hasil survei seperti tampak pada Gambar 7 menunjukkan bahwa terdapat 29\% yang menyatakan puas dan ingin lebih jauh berpartisipasi dalam MBKM, 36\% yang menyatakan puas, namun masih terdapat $17 \%$ yang menyatakan kurang puas dan $18 \%$ yang tidak berpartisipasi dalam MBKM.

Hasi survei persepsi Tendik terhadap manfaat implementasi MBKM untuk tujuan pemenuhan Capaian Pembelajaran Lulusan, dipaparkan pada Gambar 8 berikut ini:

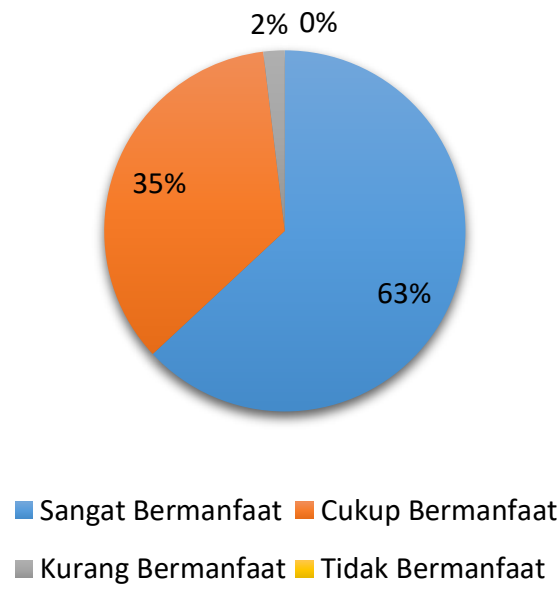

\section{Gambar 8 Pemahaman Terhadap Manfaat Implementasi MBKM Dalam Pemenuhan CPL}

Berdasarkan hasil survei seperti tampak pada Gambar 8 maka diketahui bahwa 63\% Tendik memberikan persepsi bahwa pemahaman terhadap manfaat implementasi MBKM dalam pemenuhan CPL sangat bermanfaat, $35 \%$ memberikan persepsi bahwa cukup bermanfaat, namun masih terdapat $2 \%$ yang menyatakan kurang bermanfaat.

Berikut ini adalah hasil survei persepsi Tendik terhadap pernyataan signifikan peningkatan kualitas lulusan yang dihasilkan untuk menghadapi dunia paska kampus (dunia kerja, melanjutkan kuliah, wiraswasta) jika dibandingkan dengan kondisi sebelum adanya program MBKM tampak pada Gambar 9 berikut ini:

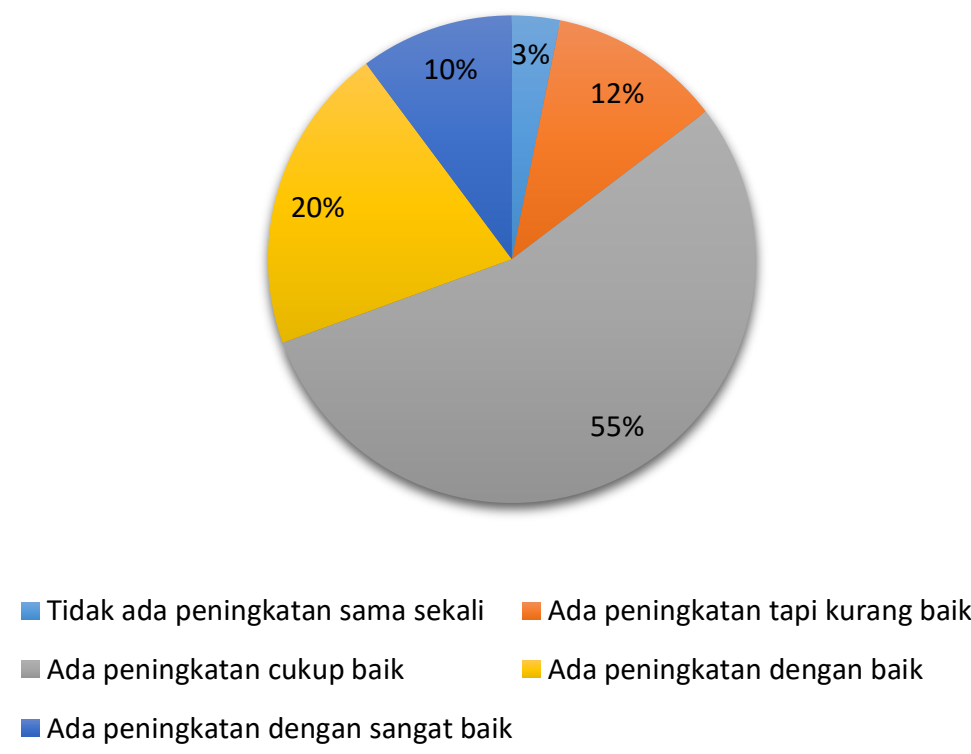

Gambar 9 Perbandingan signifikan peningkatan kualitas lulusan menghadapi dunia paska kampus 
961 Persepsi Tenaga Kependidikan Tentang Merdeka Belajar-Kampus Merdeka Studi Kasus di Universitas Flores Ende - Falentina Lucia Banda, Ernesta Leha, Reyna Virginia Nona, Lely Suryani, Konstantinus Denny Pareira Meke, Philipus N. Supardi

DOI: https://doi.org/10.31004/edukatif.v4i1.2055

Hasil survei seperti yang tampak pada Gambar 9 menunjukkan bahwa $10 \%$ menyatakan bahwa ada peningkatan dengan sangat baik terhadap kualitas lulusan menghadapi dunia paskah kampus, 20\% menyatakan ada peningkatan dengan baik, 55\% menyatakan ada peningkatan cukup baik, namun 12\% menyatakan bahwa ada peningkatan tetapi kurang baik dan 3\% menyatakan tidak ada peningkatan sama sekali. Hasil survei diatas menunjukkan bahwa perlu ada ukuran kualitas yang dipakai karena Tendik menyatakan ada peningkatan dengan ukuran kualitas yang berbeda. Tendik merekomendasikan agar program MBKM diikuti mahasiswa Universitas Flores sebanyak $81 \%$ sedangkan sisanya tidak merekomendasikan. Pada penelitian ini 4( empat) pernyataan sesuai dengan penelitian yang dilakukan oleh Nasrullah dkk, (2021). Penelitian ini terbatas pada persepsi Tendik tentang program MBKM sesuai dengan jumlah kuesioner yang diisi melalui aplikasi SPADA Dikti, belum dilakukan wawancara secara mendalam kepada Tendik terkait pemahaman tentang program MBKM. Penelitian ini selain bermanfaat untuk mendisain implementasi MBKM mulai program studi, fakultas sampai pada level universitas, juga berguna bagi pemerintah dalam hal ini Ditjen Kemendikbud dalam penetapkan kebijakan umum secara nasional terkait kesiapan implementasi MBKM di Indonesia.

\section{KESIMPULAN}

Tendik mengetahui adanya kebijakan MBKM melalui media masa, media sosial maupun sosialisasi secara luring dan daring di Universitas Flores dan akan berpartisipasi dalam implementasi MBKM melalui tugasnya masing-masing, walaupun sebagian besar Tendik belum mengetahui berapa semester dan berapa sks yang dapat disetarakan dalam program MBKM, namun Tendik berpersepsi bahwa ada peningkatan kualitas dosen, mahasiswa maupun tendik sendiri dalam implementasi MBKM di perguruan tinggi. Tendik akan berpartisipasi dalam implementasi MBKM karena dipersepsikan bermanfaat untuk meningkatkan kualitas lulusan, dan akan merekomendasikan kepada mahasiswa agar mengikuti program MBKM sesuai dengan minat mahasiswa. Sosialisasi kebijakan terkait MBKM perlu dilakukan secara berkelanjutan melalui luring/daring atau pemasangan poster atau banner dari level universitas, fakultas prodi dan unit-unit yang ada di Universitas Flores.

\section{UCAPAN TERIMA KASIH}

Ucapan terima kasih tim peneliti sampaikan kepada Ditjen Pendidikan Tinggi, Riset Dan Teknologi Direktorat Jenderal Pendidikan Tinggi, Riset Dan Teknologi Kementerian Pendidikan Dan Kebudayaan Riset Dan Teknologi yang telah mendanai penelitian ini melalui program penelitian MBKM dan pengabdian berbasis riset menggunakan bantuan pendanaan program penelitian kebijakan Merdeka Belajar Kampus Merdeka dan pengabdian kepada masyarakat berbasis hasil penelitian perguruan tinggi swasta tahun 2021. Ucapan terima kasih juga disampaikan kepada Universitas Flores dan Lembaga Penelitian dan Pengabdian Kepada Masyarakat (LP2M) Universitas Flores yang memberikan kesempatan kepada tim peneliti untuk melakukan penelitian ini, Tenaga kependidikan yang telah mengisi kuesioner survei dalam penelitian ini.

\section{DAFTAR PUSTAKA}

Dari, E. D. S. W., \& Yulhendri, Y. (2019). Analisis Kompetensi Profesional Dan Kompetensi Pedagogik Mahasiswa Pendidikan Ekonomi Universitas Negeri Padang. Jurnal Ecogen, 2(4), 757-768.

Fuadi, T. M. (2021). Konsep Merdeka Belajar-Kampus Merdeka (Mbkm): Aplikasinya Dalam Pendidikan Biologi. Prosiding Biotik, 9(1). 
962 Persepsi Tenaga Kependidikan Tentang Merdeka Belajar-Kampus Merdeka Studi Kasus di Universitas Flores Ende - Falentina Lucia Banda, Ernesta Leha, Reyna Virginia Nona, Lely Suryani, Konstantinus Denny Pareira Meke, Philipus N. Supardi

DOI: https://doi.org/10.31004/edukatif.v4i1.2055

Fuadi, T. M., \& Aswita, D. (2021). Merdeka Belajar Kampus Merdeka (Mbkm): Bagaimana Penerapan Dan Kedala Yang Dihadapi Oleh Perguruan Tinggi Swasta Di Aceh. Jurnal Dedikasi Pendidikan, 5(2), 603 614.

Hartati, S., Saputra, A. B., \& Andriani, S. (2022). Pengaruh Tingkat Pendidikan Terhadap Kinerja Pegawai Dalam Melayani Masyarakat. Edukatif: Jurnal Ilmu Pendidikan, 4(1), 298-307.

Hidayatullah, S. (2021). Persepsi Mahasiswa Tentang Kurikulum Merdeka Belajar Kampus Merdeka. Jurnal Ilmiah Fonema : Jurnal Edukasi Bahasa Dan Sastra Indonesia, 1(4), 79-87.

Indonesia, P. R. (2003). Undang-Undang Republik Indonesia Nomor 20 Tahun 2003 Tentang Sistem Pendidikan Nasional. Jakarta.

Jalaluddin, H., \& Idi, H. A. (2011). Filsafat Pendidikan: Manusia, Filsafat, Dan Pendidikan. Divisi Buku Perguruan Tinggi, Pt Rajagrafindo Persada.

Kharis, A. (2010). Pengaruh Kualitas Sumber Daya Manusia Terhadap Pelaksanaan Sistem Pengendalian Intern Pada Pt. Avia Avian. Skripsi, Upn Jawa T.

Leuhery, F. (2018). Pengaruh Kualitas Sumber Daya Manusia, Disiplin Kerja, Dan Pengembangan Karir Tehadap Prestasi Kerja Pegawai Dinas Perhubungan Provinsi Maluku. Soso-Q: Jurnal Manajemen, 6(1), $118-133$.

Nasrullah, Andi Rusfan Rizaldi, Siti Nurbaya, Sri Andayaningsih, Nurinaya, Mira. (2021). Evaluasi Pelaksanaan Bentuk Kegiatan Pembelajaran Magang Pada Program Studi Manajemen Fakultas Ekonomi Dan Bisnis, Universitas Muhammadyah Malang. Jurnal Mirai Manajemen Vol. 6, No 2 (2021) Pages 42 49

Nulhaqim, S. A., Heryadi, D. H., Pancasilawan, R., \& Ferdryansyah, M. (2016). Peranan Perguruan Tinggi Dalam Meningkatkan Kualitas Pendidikan Di Indonesia Untuk Menghadapi Asean Community 2015 Studi Kasus: Universitas Indonesia, Universitas Padjadjaran, Institut Teknologi Bandung. Share: Social Work Journal, 6(2), 197.

Pemerintah, P. (1992). No.38 Tahun 1992 Tentang Tenaga Kependidikan. Jakarta: Departemen Pendidikan Nasional.

Putri Ulfa Kamalia, Eka Hendi Andriansyah, Independent Learning-Independent Campus (Mbkm), Jurnal Kependidikan Vol. 7 No 4 December 2021

Purwono Sidik Permono, Rani Baskoro, Aji Putra, Gustiana M Anggita, Efa Nugroho.(2021) Persepsi Mahasiswa Fakultas Ilmu Keolahragaan Tentang Program Merdeka Belajar Kampus Merdeka, Jurnal Of Sport Coaching And Phisical Education. Vol 6(2) (2021) 95 - 103

Rektor, S. (N.D.). Surat Keputusan Rektor No 24 Tahun 2021. Jakarta: Departemen Pendidikan Nasional.

Riyanti, D., Irfani, S., \& Prasetyo, D. (2022). Pendidikan Berbasis Budaya Nasional Warisan Ki Hajar Dewantara. Edukatif: Jurnal Ilmu Pendidikan, 4(1), 381-390.

Rosmiati, M. (2020). Peranan Istitusi Dalam Meningkatkan Kualitas Sumber Daya Manusia Di Politeknik Negeri Bandung. Journal Of Public Administration And Local Governance, 4(2), 111-123.

Suryaman, M. (2020). Orientasi Pengembangan Kurikulum Merdeka Belajar. Seminar Nasional Pendidikan Bahasa Dan Sastra, 1(1), 13-28.

Suryaman, M., Cahyono, Y., Muliansyah, D., Bustani, O., Suryani, P., Fahlevi, M., \& Munthe, A. P. (2020). Covid-19 Pandemic And Home Online Learning System: Does It Affect The Quality Of Pharmacy School Learning. Systematic Reviews In Pharmacy, 11(8), 524-530.

Tohir, M. (2020). Merdeka Belajar: Kampus Merdeka. 